\title{
Target strength estimates of red emperor (Lutjanus sebae) with Bayesian parameter calibration
}

\author{
Sven Gastauer ${ }^{1,2, a}$, Ben Scoulding ${ }^{2}$, Sascha M.M. FÄSSLER ${ }^{2}$, Daniel P.L.D. BENDEN ${ }^{2}$ \\ and Miles PARSONS ${ }^{1}$ \\ 1 Centre for Marine Science and Technology, Curtin University, GPO Box U1987, Perth, WA 6845, Australia \\ 2 Wageningen Institute for Marine Resources and Ecosystem Studies (IMARES), PO Box 68, 1970 AB IJmuiden, The Netherlands
}

Received 31 May 2016; Accepted 18 August 2016

\begin{abstract}
Red emperor (Lutjanus sebae) is a long-lived tropical demersal snapper which is widely distributed in the Western Pacific and Indian Ocean. Despite the commercial and recreational importance of the species for the Northern Demersal Scalefish Fishery off the Northwest coast of Western Australia, we still lack a thorough understanding of its distribution and abundance in the area. To better understand the acoustic scattering properties of red emperor its acoustic backscattering characteristics were modelled based on swimbladder and body morphology, determined using computed tomography scans. A Kirchhoff-ray mode approximation was coupled with empirical (ex situ) measurements of target strength (TS) obtained from a 38 and $120 \mathrm{kHz}$ split-beam echosounder on board a fishing vessel. Bayesian methods were used for model parameter calibration, which provided uncertainty estimates for some of the TS-model parameters. The derived TS-length relationships were $19.7 \log _{10}(\mathrm{~L})-75.5$ (C.I. $5.9 \mathrm{~dB}$ ) at $120 \mathrm{kHz}$ and $14.6 \log _{10}(\mathrm{~L})-$ 64.9 (C.I. $5.8 \mathrm{~dB}$ ) at $38 \mathrm{kHz}$. The study demonstrated that small commercial fishing vessels can be used to conduct ex situ experiments and target strength modelling can be effectively based on computer tomography scans. This relatively low cost approach could be applied to other species.
\end{abstract}

Keywords: Target Strength / Bayesian inference / KRM / vessel of opportunity / Fisheries acoustics / Lutjanus sebae

\section{Introduction}

Operating in a large and dynamic environment, offshore fisheries, such as the Northern Demersal Scalefish Fishery (NDSF) in Western Australia, generally require expensive scientific surveys to support stock management. Recording calibrated multifrequency acoustic data on board vessels of opportunity could be an effective alternative to provide data on fish stock size (ICES 2007; Barbeaux et al. 2013). Red emperor (Lutjanus sebae) is a long-lived tropical demersal snapper of the Lutjanidae family. It is generally observed in reef environments, epibenthic communities, limestone sand flats and gravel patches from very shallow $(1 \mathrm{~m})$ to deeper waters $(>180 \mathrm{~m})$ (Newman and Dunk 2002). It is widely distributed throughout the Western Pacific and the Indian Ocean and made up almost half (40.15-46.96\%) of the total catches of the NDSF between 2005-2014 (Newman et al. 2014). Further, it is a popular game fishing species (Newman and Dunk 2002). To better understand its population dynamics, close collaboration with commercial stakeholders is a beneficial option.

\footnotetext{
a Corresponding author:

sven.gastauer@postgrad.curtin.edu.au
}

Echo-integration can be used to estimate fish densities within an area and thus contribute to the development of an improved sustainable management plan (ICES 2007). If acoustic echo-integration techniques (MacLennan 1990) are to be used to estimate the abundance of red emperor, an understanding of their acoustic properties is required. To convert acoustic backscatter into fish abundance or biomass, a target strength (TS, in $\mathrm{dB}$ ) to length $(\mathrm{L}$, in $\mathrm{cm}$ ) or weight ( $\mathrm{W}$, in grams) relationship is needed. TS is a logarithmic description of the proportion of incident acoustic energy backscattered from an individual target, such as a fish (Simmonds and MacLennan 2005). TS values are available for numerous commercially important and routinely surveyed pelagic species (Gauthier and Rose 2001; Ona 2003; Kloser et al. 2013). The values are determined by various methods including: empirical measurements of tethered (dead or alive) (Nakken and Olsen 1977) or caged fish (alive) (Edwards and Armstrong 1981), fish measured in situ (Soule et al. 1995), and estimates derived from mathematical models (Clay and Horne 1994; Ye 1997). In situ measurements on free-swimming individuals are deemed to provide the most representative estimates of TS. However, these are not always practicable and have limitations in species identification, target separation (Soule et al. 1995) and uncertainty in the acoustic (MacLennan and Menz 1996) and biological 
(MacLennan 1990) representation. Advances in computational power have enabled the development of complex theoretical scattering models that have been used to validate empirical TS measurements, based on morphological information of a given species in their environment (Horne et al. 2000; Foote and Francis 2002; Fässler et al. 2009, 2013). Still, the stochastic nature of TS has to be acknowledged and the resulting variance and its influence on biomass estimates have to be taken into account.

This paper describes the TS of red emperor estimated using the Kirchhoff-ray mode approximation (KRM) (Clay and Horne 1994) with a Bayesian estimation approach (Fässler et al. 2009). Computed tomography (CT) scans were conducted to measure swimbladder and fish body morphology for use in the KRM model. The empirical ex situ TS data were used to validate and fit the model. The model includes a Bayesian estimation component to deal with variability in orientation - one of the main factors influencing the backscatter of a fish (Hazen and Horne 2003). Few studies have utilised a Bayesian approach to model TS before, even though its benefits, including improved variance estimates by being informed by data and expert judgement, are widely recognised (Hammond 1997; Fässler et al. 2009).

\section{Material and methods}

\section{Fish samples}

Specimens of red emperor were collected on the 7 th and 8th of March 2015 , between $14.46^{\circ}$ and $17.57^{\circ} \mathrm{S}$, and $121.47^{\circ}$ and $121.52^{\circ} \mathrm{E}$, at depths around $70 \mathrm{~m}$, during a dedicated research trip on the chartered trap fishing vessel "Carolina M" ( $\approx 15 \mathrm{~m}$ in length). All samples were caught using standard commercial steel trap cages, with a mesh size of $5 \mathrm{~cm}$. Traps were pulled on board as slowly as possible to avoid potential damage to the swimbladder that can occur from rapid pressure changes in water. Red emperor is known to be very robust against barotrauma and swimbladder ruptures, and can acclimatise to depth very quickly (Brown et al. 2010). Once on deck the fish were acclimated in a well oxygenated tank for 24 hours which allowed the swimbladder to adjust to water pressure at the surface. Some specimens were used for cage experiments and others for fish scans.

\section{Ex situ cage experiments}

All ex situ measurements were made with a hull-mounted $38 \mathrm{kHz}$ and $120 \mathrm{kHz}$ split-beam SIMRAD ES70 echosounder. The echosounders were calibrated using a $38.1 \mathrm{~mm}$ tungsten carbide (WC) sphere prior to the investigation period, following standard sphere procedures (Demer et al. 2015). A pulse duration of $1.024 \mathrm{~ms}$ with a power of $2000 \mathrm{~W}$ was used for the $38 \mathrm{kHz}$ transducer, whilst a pulse duration of $0.064 \mathrm{~ms}$ and a power of $1000 \mathrm{~W}$ was used for the $120 \mathrm{kHz}$ transducer. The pulse durations and power inputs were kept at the settings normally used by the fishermen, to allow for best compatibility with acoustic data collected during routine operations.

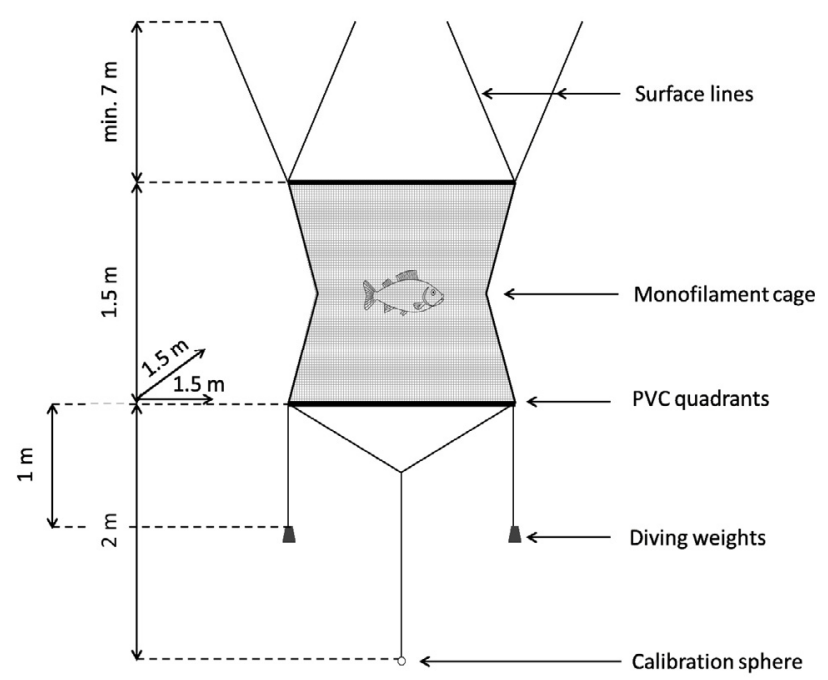

Fig. 1. Monofilament experimental cage setup used for measuring target strength ex situ with indication of the attached weights, calibration sphere and cameras.

Given the power settings were above the recommended settings (Korneliussen et al. 2008), tank calibration experiments were conducted to test for potential bias in the recorded data, but no abnormalities could be detected. The ping rate was set to the maximum. TS of individual red emperors were measured in a custom built $1.5 \times 1.5 \times 1.5 \mathrm{~m}$ monofilament cage suspended $>7 \mathrm{~m}$ below the transducer, which is outside the nearfield zone (near-field at $38 \mathrm{kHz}$ and $120 \mathrm{kHz}$, with $7^{\circ}$ nominal beam widths, were $2.75 \mathrm{~m}$ and $0.89 \mathrm{~m}$, respectively). The cage could be manually manoeuvred to maintain its position within the acoustic beam by four point attachments using hand-lines on the deck (Fig. 1). The cage was held together at the top and bottom by hollow water-filled PVC tubes. To prevent the fish from resting in the cage corners, the mesh was knitted together so that a dent was left in the centre of the cage. This made the edges harder to access. Multiple 500 gram diving weights were attached to the cage bottom. This aided in sinking and provided improved stability once at depth. This was of particular importance, given the strong tidal currents that can be found in the research area. A $38.1 \mathrm{~mm}$ WC sphere was attached $2 \mathrm{~m}$ below the cage to provide reference values and to measure the performance of the system. After the ex situ measurements, the fish were placed in an ice slurry and then frozen for radiographic imagery. Total length (TL, to the nearest $0.5 \mathrm{~cm}$ ) and total weight (TW, in grams) of each specimen were measured. Five experiments containing one fish each were conducted.

All acoustic data were corrected for triangular wave error (Ryan and Kloser 2004) and calibration settings were applied prior to the post-processing procedure in Echoview 6.1 (Echoview Software Pty Ltd 2015). Firstly, a single target detection algorithm (e.g. Soule et al. 1997) was used to isolate single fish targets within the cage boundaries. Next, an alphabeta target tracking algorithm (Blackman 1986) was used to assign individual targets to tracks based on user-defined criteria (TS Threshold $=-50 \mathrm{~dB}$; Maximum beam compensation $=6 \mathrm{~dB}$; Maximum standard deviation of Minor- or Majoraxis $=0.6^{\circ}$ ). The algorithm predicted target locations based on 
Table 1. Constant parameter values used for Kirchhoff-Ray model of red emperor target strength.

\begin{tabular}{ccccc}
\hline Description & Symbol & Value & Unit & Source \\
\hline Density of sea water & $\rho_{\mathrm{w}}$ & 1026 & $\mathrm{~kg} / \mathrm{m}^{3}$ & Gauthier and Horne (2004) \\
Density of fish body & $\rho_{\mathrm{fb}}$ & 1071 & $\mathrm{~kg} / \mathrm{m}^{3}$ & Fässler et al. (2009) \\
Density of swimbladder gas & $\rho_{\mathrm{sb}}$ & 2.64 & $\mathrm{~kg} / \mathrm{m}^{3}$ & Clay et al. (1991) \\
Sound speed of sea water & $c_{\mathrm{w}}$ & 1541.2 & $\mathrm{~m} \mathrm{~s}^{-1}$ & CTD measurements \\
Sound speed in fish body & $c_{\mathrm{fb}}$ & 1570 & $\mathrm{~m} \mathrm{~s}^{-1}$ & Gauthier and Horne (2004) \\
Sound speed in swimbladder & $c_{\mathrm{sb}}$ & 340 & $\mathrm{~m} \mathrm{~s}^{-1}$ & Yasuma et al. (2010) \\
Echosounder frequency & $F$ & 38,120 & $\mathrm{kHz}$ & - \\
Tilt angle & $\Theta$ & {$[50,130]$} & $\circ$ & - \\
\hline
\end{tabular}

position (the alpha parameter) and velocity (the beta parameter) of targets at previous ping(s), following a set of acceptance rules. Target tracking allowed investigation of the TS variation associated with individual fish.

The bootstrapped mean TS, standard deviation (SD) and confidence intervals at $95 \%$ of all tracks was used to solve the TS-L equation of the form $T S=m \log _{10}(L)+b_{20}$ where $b_{20}$ is a intercept value, $m$ describes the slope and $L$ is the total length of the fish (in cm) (Simmonds and MacLennan 2005). To understand the tilt angle distribution of the ex situ recordings, the tilt angle $(\theta)$ of the fish tracks was approximated using the change in height $(\delta(h))$ and distance, observed in 3D space $\left(z_{3 \mathrm{D}}\right)$, with $\theta=\operatorname{cosine}\left(\frac{\delta(h)}{z_{3 D}}\right)$ (Ona 2001).

\section{Fish scans}

A CT scanner (Siemens SOMATOM Dual Energy 64 slices) was used to measure the dimensions and shapes of the fish body and swimbladder, which are used as inputs to the KRM backscatter model. Prior to scanning, specimens were placed on a styrofoam pedestal (invisible to the scanner), resting on the dorsoventral axis. Data were stored in the standard DICOM format with an in-plane resolution of $0.3-$ $0.52 \mathrm{~mm}$ and slice spacing of $0.6 \mathrm{~mm}$. Fish and swimbladder shapes were extracted using a purpose built software tool, developed in Python 2.7 (Python Software Foundation, https:// www.python.org/). The software allowed DICOM files or folders to be read in and displayed in the available coronal and sagittal planes, with an additional axial view. Various filters (i.e. mean, median, erosion, inversion and binary transformation) were applied to improve the contour extraction algorithm. The software outputs .csv files containing the vertical extreme points of the fish and swimbladder on each slice ( $x_{\text {upper }}$ and $\left.x_{\text {lower }}\right)$ and the corresponding width. The resulting extremes of fish body and swimbladder dimensions on each slice were used to approximate these 3D shapes respectively as a series of fluid- and gas-filled cylinders. These shape approximations were then used as input for the KRM, modelling TS for each of the fish individually. The software also produces a 3D-mesh STL file. This mesh was used to construct a 3D representation of the swimbladder and to determine the respective volume and length coordinates of the entire swimbladder surface.

\section{Kirchhoff-ray-mode model}

The KRM model (Clay and Horne 1994) calculates the combined backscatter of an object as the summed contributions of consecutive short, gas- or fluid-filled cylinders (Clay and Horne 1994). The fish body and the gas-bearing swimbladder were modelled as respective sets of fluid- and gasfilled cylinders. The backscatter was expressed as Reduced Scattering Length (RSL). RSL refers to the estimated scattering length, normalised by the fish caudal length $(L)$. In other words, the RSL is the cumulative sum of backscattering crosssections $\left(\sigma_{\mathrm{bs}}\right)$ of each finite cylinder. RSL relates to TS by:

$$
T S=10 \log _{10}\left(R S L^{2} \times L^{2}\right) .
$$

Sound speed and density contrasts of sea water, swimbladder and fish body were assumed to be fixed (Table 1). Using the information from the fish scans and changing the tilt angle parameter in the KRM model, $R S L$ and subsequently $T S$ were computed over a range of tilt angles $\left(\theta ; 50\right.$ to $\left.130^{\circ}\right)$ to represent the potential orientation range exhibited by the fish. Total fish backscatter was calculated as the combined summation of backscatter contributions of both swimbladder and fish body cylindrical elements (Clay and Horne 1994).

\section{Bayesian estimation of model parameters}

A flowchart of the Bayesian parameter estimation process can be found in Figure 2. Model parameter estimation can be achieved with different methods. An advantage of using Bayesian inference is that it provides an unambiguous way to combine observations with prior knowledge about model parameters (Hartig et al. 2012). The resulting joint conditional posterior probability distribution $p(A \mid d a t a)$ for model parameters $A$, given the data, is calculated using Bayes' theorem:

$$
p(A \mid \text { data })=\frac{p(\text { data } \mid A) \times p(A)}{p(\text { data })},
$$

where $p($ data $\mid \mathrm{A})$ denotes the likelihood function and describes the probability of obtaining the data with the given model parameters $A$. Here, the "data" were the ex situ TS measurements obtained from the caged fish, and "model" was the KRM TS model. Uniform distributions were used as priors for the two non-fixed parameters, as little information on these parameters 


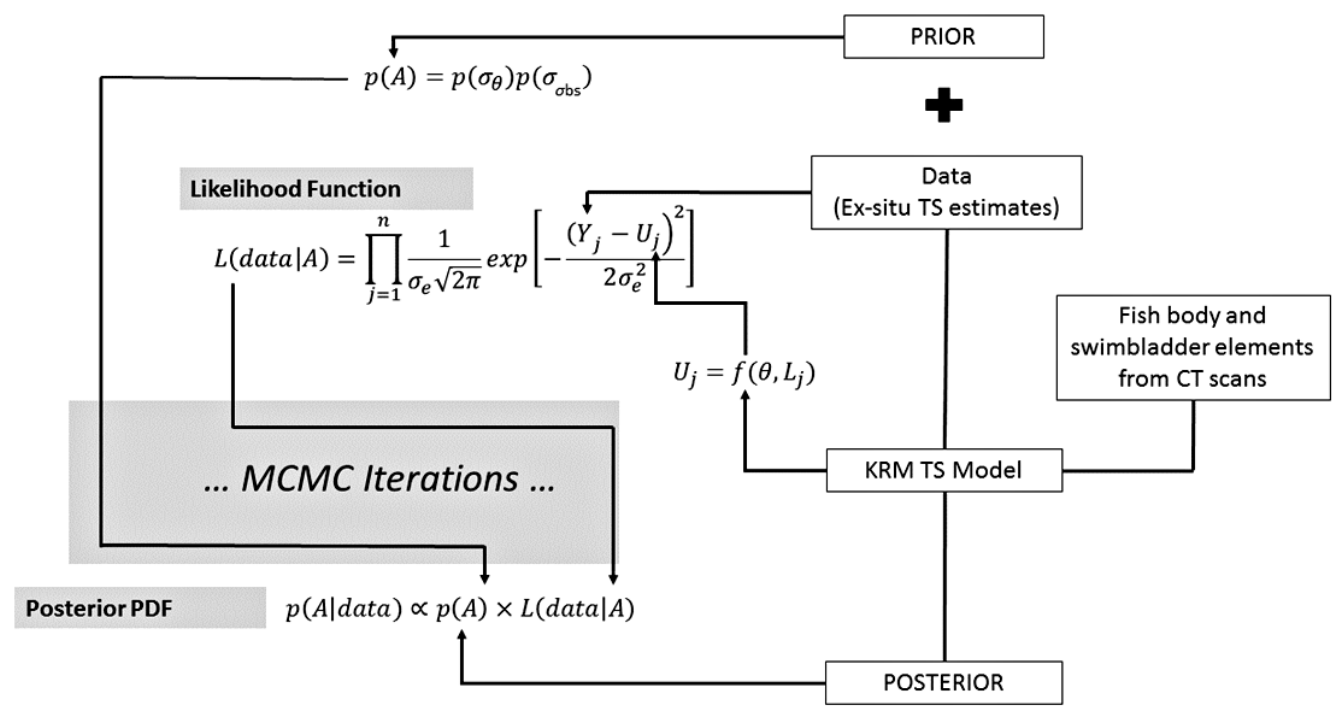

Fig. 2. Flow chart illustrating the Bayesian parameter estimation process; the posterior PDF with the parameters (A) given the data (based on ex-situ experiments) is computed based on uniform prior information (standard deviation of tilt angle $\left(\sigma_{\theta}\right)$ and the standard deviation of mean backscattering cross-sections $\left(\sigma_{\mathrm{bs}}\right)$ ) and the likelihood of the data, given the parameters A, estimated based on length dependent TS $Y_{j}$ ) from the data and modelled tilt angle and length dependent TS estimates $\left(U_{j}\right)$ from the KRM model where $\sigma_{e} i$ s the standard deviation of the error.

was available beforehand. The term $p$ (data) is a normalising constant.

Assuming normality the likelihood function is

$$
L(\operatorname{data} \mid A)=\prod_{j=1}^{n} \frac{1}{\sigma_{e} \sqrt{2 \pi}} \exp \left[-\frac{\left(Y_{j}-U_{j}\right)^{2}}{2 \sigma_{e}^{2}}\right],
$$

with $Y_{j}$ the $j$ th observed TS value and $U_{j}$ the TS value predicted with the KRM model using parameters values $A$ together with fixed values for sound speed and density contrasts of sea water, swimbladder and fish body (Table 1).

Two model parameters $(A)$ were estimated: the standard deviation of the tilt angle distribution $\left(S D_{\theta}\right)$ for which a uniform prior distribution $\left(S D_{\theta} \sim \operatorname{Uniform}(0.01,1)\right)$ was used, and the standard deviation of mean backscattering cross-sections $\left(S D_{\sigma \mathrm{bs}}\right)$, again a uniform prior distribution $\left(S D_{\sigma \mathrm{bs}} \sim\right.$ Uniform $(0.001,1)$ ) was used (Hazen and Horne 2003). Both priors were defined independently, as well as independent from fish length $(L)$, standard deviation of fish length $\left(S D_{\mathrm{L}}\right)$, and all density and sound speed contrasts.

Bayesian computation was carried out through MetropolisHastings Markov chain Monte Carlo sampling (MCMC) (Metropolis et al. 1953) using R 3.2.5 (R Core Team 2016). Posterior distributions converged prior to 200 iterations; however, the first 2000 samples were conservatively discarded as burn in phase. The subsequent 10000 samples from the joint posterior distribution were then retained.

As the samples from the posterior distributions of the two parameters were independent for all fishes, separate parametric distributions were fitted to the marginal posterior parameter values. The marginal posterior distribution of $S D_{\theta}$ was best described by a normal distribution of the shape:

$$
f(x)=\frac{1}{\sqrt{(2 \pi)} \sigma} e^{\frac{(x-u)^{2}}{2 \sigma^{2}}},
$$

where $\mu$ is the mean of the distribution and $\sigma$ the standard deviation. The posterior distribution of $S D_{\sigma \mathrm{bs}}$ was described by a gamma distribution of the shape:

$$
f(x)=\frac{1}{s_{s c} y\left(s_{s h}\right) x^{\left(s_{s h}-1\right)} e^{-\left(x / s_{s c}\right)}},
$$

with $s_{\mathrm{sh}}$ being the shape and $s_{\mathrm{sc}}$ the scale parameter.

\section{Results}

\section{Ex situ TS measurements}

Three out of a total of five cage experiments, each containing a different fish, were used for further analyses based on data quality and quantity. The three fish measured 45, 52 and $53 \mathrm{~cm}$ (Table 2). Even if the number of fish measured is low, they still represent a relatively good coverage of the most typically observed size classes in the area (mean length $=51.97 \mathrm{~cm} ; S D \pm 8.51 \mathrm{~cm}$, based on 751 commercially caught red emperor). Unsuccessful experiment runs were mostly characterised by fish resting in corners or very close to the bottom of the cage for considerable amounts of time. The three analysed experiments delivered recordings of 33 tracks comprising 268 positively identified fish targets at $38 \mathrm{kHz}$ and 48 tracks with 258 targets at $120 \mathrm{kHz}$ (Table 2). Mean ex situ TS values were based on 10000 non-parametric bootstrap samples from the recorded data. Mean TS, SD and parameter $b_{20}$ of the TS-L relationship were computed for each of the three fish (Table 2). Calculating the mean $b_{20}$ parameter for the combined measurements gave:

$$
\begin{aligned}
T S_{38} & =20 \log _{10}(L)-73.9 \\
T S_{120} & =20 \log _{10}(L)-79.4
\end{aligned}
$$


Table 2. Mean TS at 38 and $120 \mathrm{kHz}$ for three ex situ measured red emperors, based on detected fish tracks with an indication of the number of fish tracks and targets identified for each specimen.

\begin{tabular}{ccccccccc}
\hline & $38 \mathrm{kHz}$ & & \multicolumn{6}{c}{$120 \mathrm{kHz}$} \\
\hline $\begin{array}{c}\text { Fish size } \\
{[\mathrm{cm}]}\end{array}$ & $\begin{array}{c}\text { No } \\
\text { tracks }\end{array}$ & $\begin{array}{c}\text { No } \\
\text { targets }\end{array}$ & $\begin{array}{c}\text { Mean } \\
\text { TS [dB] }\end{array}$ & SD & Tracks & Targets & $\begin{array}{c}\text { Mean } \\
\text { TS [dB] }\end{array}$ & SD \\
\hline 45 & 19 & 176 & -42.5 & 1.3 & 12 & 53 & -47.8 & 0.8 \\
52 & 8 & 38 & -38.8 & 1.4 & 27 & 105 & -44.9 & 1.8 \\
53 & 6 & 54 & -37.4 & 1.6 & 9 & 100 & -43.7 & 1.9 \\
\hline
\end{tabular}
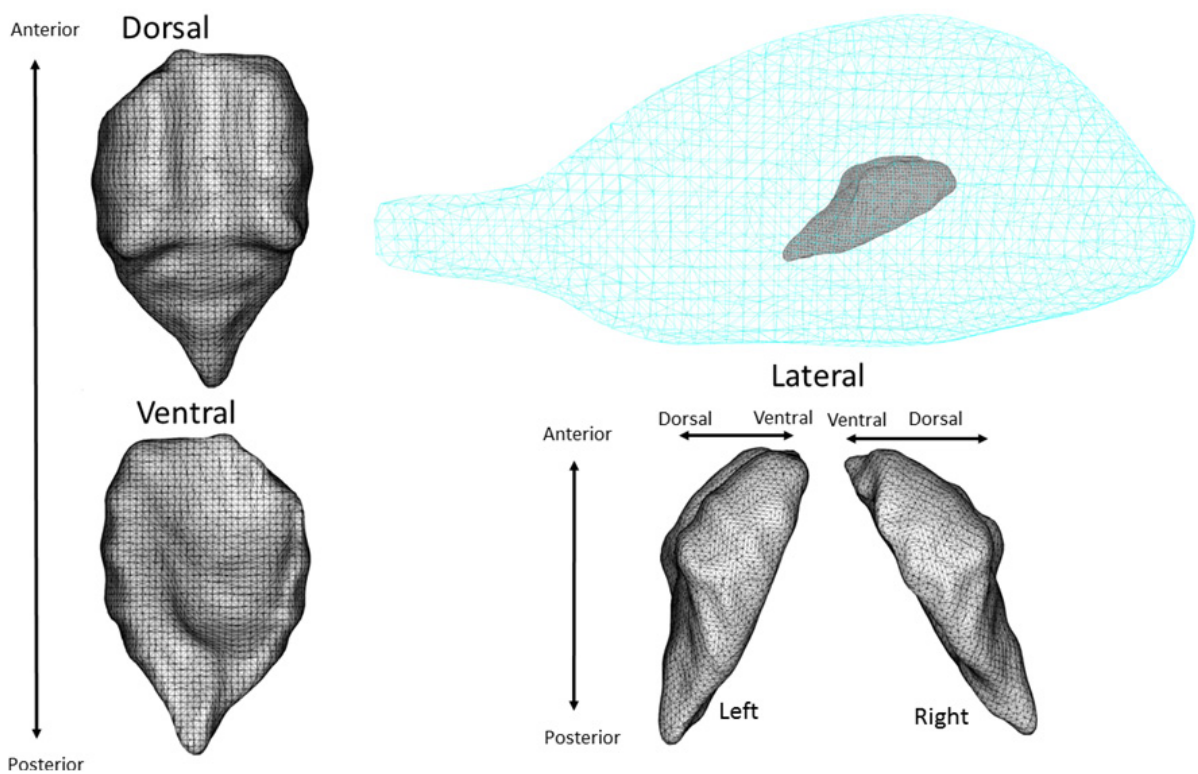

Fig. 3. Example of a red emperor swimbladder reconstructed from computer tomography measurements shown from different perspectives and a mesh of the fish body with an indication of the swimbladder location.

Tilt angles of individuals measured in the cage at $38 \mathrm{kHz}$ ranged from $80.2-97.9^{\circ}$ with a mean of $89.4^{\circ}\left(S D \pm 3.8^{\circ}\right)$. At $120 \mathrm{kHz}$, tilt angles varied between $78.4-98.6^{\circ}$ with a mean of $90.5^{\circ}\left(S D \pm 4.43^{\circ}\right)$.

\section{Morphology of the swimbladder}

Nine red emperor were scanned in total, but only three fish had intact swimbladders that were deemed in good condition (no rupture to the outline of the swimbladder or complete deflation of the swimbladder). The other six fish all showed signs of swimbladder rupture that were possibly caused during capture, handling or preparation. The scanned fish had TLs of 41,43 and $54 \mathrm{~cm}$, with TWs of 1054,1159 and $2373 \mathrm{~g}$, and swimbladder lengths of $7.1,6.6$ and $7.3 \mathrm{~cm}$, respectively. The swimbladders were dorsoventrally compressed and rostrocaudally elongated. The front section appeared concave with two fairly symmetrical humps on the underside of the swimbladder (Fig. 3). The overall shape of the front was approximately cube-like, while the back part was almost triangular. The swimbladder was inclined at an angle of approximately 20-30 head-up relative to the fish axis (Fig. 3).

\section{TS estimation}

Mean $S D \sigma_{\mathrm{bs}}$ at $38 \mathrm{kHz}$ was estimated to be $6.1 \mathrm{~dB}$ and $6.0 \mathrm{~dB}$ at $120 \mathrm{kHz}$. Mean $S D_{\theta}$ at $38 \mathrm{kHz}$ was $5.8^{\circ}$ and $5.9^{\circ}$ at $120 \mathrm{kHz}$. Fitting the TS-L equation to the KRM model outcome resulted in (Fig. 4):

$$
\begin{aligned}
& T S_{38}=14.6 \log _{10}(L)-64.9\left(\text { S.E. }=1.47, \quad \mathrm{R}^{2}=0.60\right) \\
& T S_{120}=19.7 \log _{10}(L)-75.5\left(\text { S.E. }=1.70, \quad R^{2}=0.65\right) \text {. }
\end{aligned}
$$

Estimated TS and confidence intervals over the entire range of tilt angles for the three scanned fish at $38 \mathrm{kHz}$ were $-41.4 \pm$ $5.5 \mathrm{~dB},-41.4 \pm 5.4 \mathrm{~dB}$ and $39.6 \pm 5.2 \mathrm{~dB}$ for fish sizes 41 , $43,54 \mathrm{~cm}$, respectively. At $120 \mathrm{kHz}$ estimated TS and confidence intervals were $-43.7 \pm 5.8 \mathrm{~dB},-43.4 \pm 5.7 \mathrm{~dB}$ and $41.4 \pm 5.4 \mathrm{~dB}$. Based on these three measurements TS was $2.1 \mathrm{~dB}$ higher at $38 \mathrm{kHz}$ compared to $120 \mathrm{kHz}$. Comparing predicted TS for fish of size $30-60 \mathrm{~cm}$ resulted in a mean $\mathrm{dB}$ difference of $2.2 \mathrm{~dB}$, stronger at $38 \mathrm{kHz}$ than at $120 \mathrm{kHz}$. Tilt angle-specific TS were computed based on different values of $\theta$ (Fig. 5). All three fish displayed a slightly different pattern, but troughs and peaks were generally found at similar tilt angles, with troughs located around $60^{\circ}, 80-90^{\circ}$ and $95-110^{\circ}$. This pattern was prominent at $38 \mathrm{kHz}$, while a similar pattern 


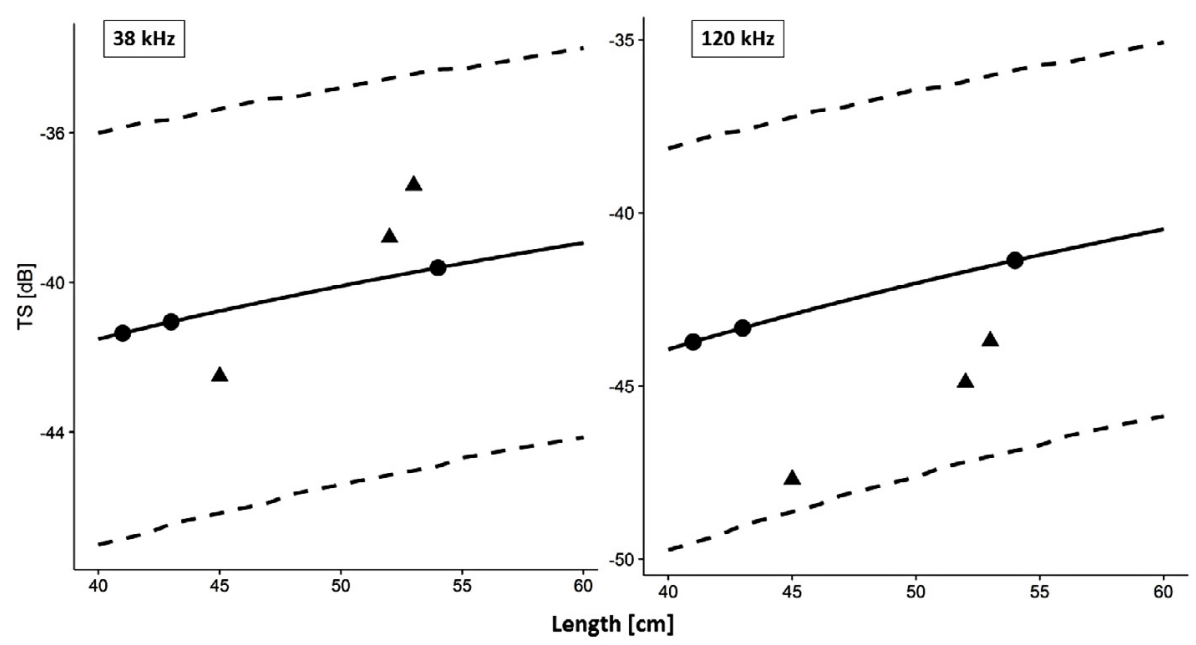

Fig. 4. Red emperor estimated TS at length relationship with $95 \%$ confidence intervals estimated using KRM model parameter values estimated by a Bayesian approach at $38 \mathrm{kHz}$ (a) and $120 \mathrm{kHz}$ (b). Filled circles indicate the total length of fishes for which swimbladder and body measurements were available. Ex situ TS measurements of three fishes are indicated as triangles.
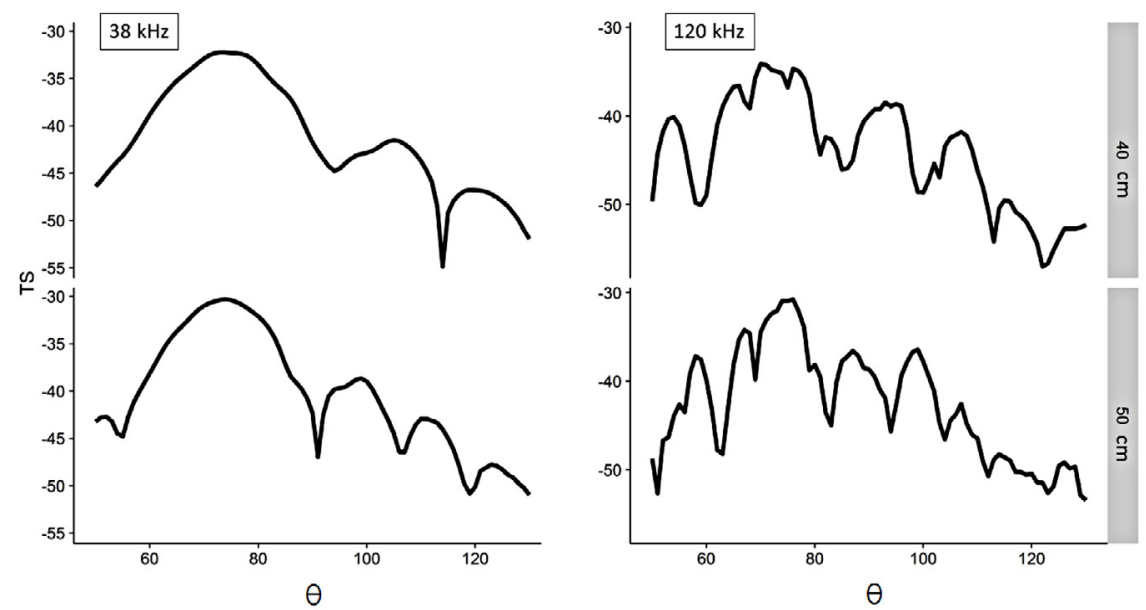

Fig. 5. Estimated TS for red emperor for tilt angle $\theta$ ranging from 50 to $130^{\circ}$ modelled for hypothetical fish of size 40 and $50 \mathrm{~cm}$ at $38 \mathrm{kHz}$ (a) and $120 \mathrm{kHz}(\mathrm{b})$.

with more complexity was observed at $120 \mathrm{kHz}$. Figures $5 \mathrm{a}$ and $5 \mathrm{~b}$ illustrate this pattern, modelled for two hypothetical fish of length 40 and $50 \mathrm{~cm}$, respectively.

\section{Discussion}

The experimental technique used to estimate TS can have an influence on the outcome. Empirical in situ TS measurements should deliver the most representative measures of TS (Simmonds and MacLennan 2005) as observations are based on fish behaving "naturally" in their normal environment. In situ TS measurements were impracticable in the given situation, as red emperor is generally found within dense, mixed schools, close to the seabed. In comparison, ex situ measurements can be made, allowing for easier target discrimination, and a more controlled environment. Nonetheless, differences have been observed between TS of living, dead, and stunned fish (McClatchie et al. 1996). The setup of the ex situ measurements probably limited the movement of the fish. For the majority of the time fish were moving in a rather horizontal manner with the observed range of tilt angles ranging from approximately $80^{\circ}$ to $100^{\circ}$. They would typically move slowly upwards from the trap and then swim around for a little while, before resting on the bottom of the trap again. Even though all specimens appeared to be swimming freely when put into the cage, the depth at which they were measured could have influenced their behaviour, just as the fact that they were kept in a cage. Only three fish could be measured successfully, due to the prevailing difficult conditions with very strong currents, limited time available at sea and the low number of good condition fish samples available. Despite the limited number of fish, we propose that as the first TS measures of a data poor species our results are a valuable starting point upon which future studies may build.

The main contributor to the amplitude of the speciesspecific acoustic backscatter of fish is the swimbladder, when present (Foote 1980b; Ona 1990; Foote and Francis 2002). For a given species, however, TS is predominantly influenced by 
fish length (Love 1977; Foote 1979) and orientation (Nakken and Olsen 1977; Foote 1980a). Most empirical TS measurements have traditionally been derived from in situ or ex situ measurements. However, with advancements in computational power, modelling techniques have become widely used (Horne et al. 2000; Fässler et al. 2013; Scoulding et al. 2015). Previous studies have successfully used CT scans to derive morphological representations of swimbladders as an alternative to time consuming and more expensive methods such as microtoming or MRI scans (Reeder et al. 2004; Peña 2008; Fässler et al. 2013; Scoulding et al. 2015). CT scanning provides high resolution data to reconstruct detailed 3D images of the swimbladder and the fish body for use in backscatter modelling (Macaulay 2002; Reeder et al. 2004). It also provides a noninvasive method to describe the position of the swimbladder within the fish body.

One of the main advantages of a modelling approach is the ability to investigate the effects of various factors (e.g. orientation and size) on TS estimates. Inherently, these are difficult to control in empirically derived estimates of TS (Clay and Horne 1994; Foote and Francis 2002; Fässler et al. 2009). The model approach selected here may not be universally suitable to all species or frequencies. Approximated shapes of the swimbladder and fish body were used in combination. Whilst this is applicable for the acoustic frequencies and species investigated here, other body parts or fine-scale details of the swimbladder or the fish shape may have a greater influence on backscatter. Model choice can have a significant effect on TS estimates (Macaulay et al. 2013). Backscatter modelling remains a trade-off between computational power and model complexity. This results in a compromise between simplicity and the need to capture the true anatomical complexity and material properties that contribute to TS variation of a fish.

Further, models can assist in uncertainty estimation (Kloser and Horne 2003; Demer 2004; Fässler et al. 2009). The Bayesian model parameter estimation applied here, which essentially "calibrated" the KRM model on the basis of ex situ TS measurements, facilitated the estimation of uncertainty in unknown parameters or parameters that are notoriously difficult to estimate. Combining these estimates in a TS model allowed for uncertainty associated with the resultant TS distribution. Nonetheless, the approach may still introduce bias in some situations. A potential shortcoming of the applied Bayesian approach for model parameter estimation is the need to select (objective) priors for the parameters. A potentially unrealistic prior may have a severe impact on model outcomes (McAllister and Kirkwood 1998). Informative priors therefore, should only be used if the a priori knowledge about a parameter to be estimated is deemed reliable. In the present study, vaguely informative priors, i.e. lower and upper plausible values, were chosen for the parameters to be estimated, as adequate knowledge about their expected values was absent.

Other studies that have compared modelled estimates of TS with empirical measurements (i.e. in situ or ex situ) found good agreement (Hazen and Horne 2004; Henderson and Horne 2007; Peña and Foote 2008). Measured $S D_{\log (\sigma \mathrm{bs})}$ and $S D_{\theta}$ were very similar for all fish used in the cage experiment at both frequencies (Table 2). Comparing the modelled estimates to ex situ measurements, we found reasonable agree- ment at $38 \mathrm{kHz}$ and ex situ values spread around the modelled relationship (Fig. 4). Modelled $T S_{38}$ values were on average $-0.2 \mathrm{~dB}(S D \pm 0.3 \mathrm{~dB})$ lower than those estimated by the ex situ experiments. For $120 \mathrm{kHz}$ the shape of the fitted TS model relationship was very similar for both modelled and ex situ values, but were in general estimated to be stronger (mean $3.4 \mathrm{~dB}$, $S D \pm 0.02 \mathrm{~dB}$ ). A possible explanation for the differences between modelled and measured values could be the spread of tilt angles. As mentioned previously, the entire range of tilt angles could not be measured during the ex situ measurements. TS measured ex situ, only detected tilt angles close to $90^{\circ}$, which coincides with a trough in the estimated tilt angle dependent TS (Fig. 5). The higher resolution of the $120 \mathrm{kHz}$ data, due to the much lower pulse duration, could possibly pick up minor details in the physiological characteristics of the swimbladder. This effect could have had a stronger impact at some tilt angles. Generally, the larger the ratio of the target length to acoustic wavelength, the greater the influence of directivity (McCartney and Stubbs 1971). The potential effect is illustrated by the estimated TS for different tilt angles (Fig. 5). Fluctuations were more pronounced at the higher frequency. While the $38 \mathrm{kHz}$ estimates showed a maximum of five peaks and troughs, a multitude were observed at $120 \mathrm{kHz}$, hence the effect of the recorded tilt angle was much stronger at $120 \mathrm{kHz}$.

Previous studies have analysed the TS for other Lutjanid species (Au and Benoit-Bird 2003; Benoit-Bird and Au 2003). These studies used different frequencies but found in general higher TS values compared to the current study. However, $\mathrm{Au}$ and Benoit-Bird (2003) observed troughs in amplitude at around $120 \mathrm{kHz}$ and at the lower frequencies, which might explain part of the $\mathrm{dB}$ difference. Another possible explanation could be the different angle at which the swimbladder is positioned in the species, which varied largely.

The use of multifrequency characteristics to identify species or target groups during the scrutinising process is commonplace in fish surveys. In the present study, TS for red emperor was estimated at 38 and $120 \mathrm{kHz}$ and a relatively stable $\mathrm{dB}$ difference, approximately $2 \mathrm{~dB}$ stronger at $38 \mathrm{kHz}$, was detected. This relationship may become useful to distinguish different species occurring in the same area once there are more measurements available. Multi-frequency discrimination of species will be enhanced if backscatter was measured simultaneously at more than two frequencies. At the time of the ex situ experiments 38 and $120 \mathrm{kHz}$ were the only two frequencies available in the field with split-beam capabilities. Nonetheless, the presented data remains highly valuable in a data poor area such as the Northern Demersal Scalefish Fishery.

The $38 \mathrm{kHz}$ data provided more stable TS measures that varied less with tilt angle, and showed a better agreement between modelled and measured TS. Therefore, it would be recommended to base any acoustic biomass or abundance estimates for red emperors on $38 \mathrm{kHz}$ data rather than using a higher frequency.

The study showed that a Bayesian calibration of TS model parameters can be used to describe the joint parameter distribution that contributes to the total precision of the TS estimate. The present study demonstrated how relatively low cost, small-scale commercial fishing vessels can be used to carry out 
ex situ TS experiments. Such an approach could be applied to a multitude of species and could improve the general understanding of scattering properties of species that do not have the benefits of regular acoustic survey coverage.

Acknowledgements. The authors would like to thank ICES WGFAST, WGTC and the SOMEACOUSTICS Symposium for fruitful discussions and support. CSIRO and especially Lionel Esteban for support with the CT scans. Alison Lynton from ICT at Curtin University for support. Echoview for software and support. Funding for this research was received from the Australian Government via the Fisheries Research and Development Corporation (FRDC), with support from the Western Australian Department of Fisheries. SOMEACOUSTICS and IMARES provided the main author with a gratefully received student fund to present this research. A special thank you to Kimberley Wildcatch and the crew of Carolina M., as well as Adam and Alison Masters for their support and help during the data collection process.

\section{References}

Au W.W., Benoit-Bird K.J., 2003, Acoustic backscattering by Hawaiian lutjanid snappers. II. Broadband temporal and spectral structure. J. Acoust. Soc. Am. 114, 2767-2774.

Barbeaux S.J., Horne J.K., Dorn M.W., 2013, Characterizing walleye pollock (Theragra chalcogramma) winter distribution from opportunistic acoustic data. ICES J. Mar. Sci. 70, 1162-1173.

Benoit-Bird K.J., Au W.W., Kelley C.D., 2003, Acoustic backscattering by Hawaiian lutjanid snappers. I. Target strength and swimbladder characteristics. J. Acoust. Soc. Am., 114, 2757-2766.

Blackman S.S., Norwood, Massachusetts: Artech House Inc., 1986, Multiple-Target Tracking with Radar Applications, 464 pp.

Brown I., Sumpton W., McLennan M., Mayer D., Campbell M., Kirkwood J., Butcher A., Halliday I., Mapleston A., Welch D., Begg G.A., Sawynok B., 2010, An improved technique for estimating short-term survival of released line-caught fish, and an application comparing barotrauma-relief methods in red emperor (Lutjanus sebae Cuvier 1816), J. Exp. Mar. Biol. Ecol. 385, 1-7.

Clay C.S., Horne J.K. 1994, Acoustic models of fish: The Atlantic cod (Gadus morhua). J. Acoust. Soc. Am. 96, 1661-1668.

Demer D.A., 2004, An estimate of error for the CCAMLR 2000 survey estimate of krill biomass. Deep Sea Res. Part II Top. Stud. Oceanogr. 51, 1237-1251.

Demer D.A., et al. 2015, Calibration of acoustic instruments. ICES CRR No. 326. 133 p.

Echoview Software Pty Ltd, 2015, Echoview software, version 6.1.44. Echoview Software Pty Ltd, Hobart, Australia

Edwards J.I., Armstrong F., 1981, Measurements of the target strength of live herring and mackerel. ICES CM/ B:26, pp. 5-11.

Fässler S.M.M., Brierley A.S., Fernandes P.G., 2009, A Bayesian approach to estimating target strength. ICES J. Mar. Sci. 66, 11971204.

Fässler S.M.M., O'Donnell C. Jech J.M., 2013, Boarfish (Capros aper) target strength modelled from magnetic resonance imaging (MRI) scans of its swimbladder. ICES J. Mar. Sci. 70, 14511459 .

Foote K.G., 1979, On representing the length dependence of acoustic target strengths of fish. J. Fish. Board Can. 36, 1490-1496.

Foote K.G., 1980a, Averaging of fish target strength functions. J. Acoust. Soc. Am. 67, 504-515.
Foote K.G., 1980b, Importance of the swimbladder in acoustic scattering by fish: A comparison of Gadoid and mackerel target strengths. J. Acoust. Soc. Am. 67, 2084-2089.

Foote K.G., Francis D.T.I., 2002, Comparing Kirchhoffapproximation and boundary-element models for computing gadoid target strengths. J. Acoust. Soc. Am. 111, 1644-1654.

Gauthier S., Rose G.A., 2001, Target Strength of encaged Atlantic redfish (Sebastes spp.). ICES J. Mar. Sci. 58, 562-568.

Hammond T., 1997, A Bayesian interpretation of target strength data from the Grand Banks. Can. J. Fish. Aquat. Sci. 54, 2323-2333.

Hartig F., Dyke J., Hickler T., Higgins S.I., O’Hara R.B., Scheiter S., Huth A., 2012, Connecting dynamic vegetation models to data an inverse perspective. J. Biogeogr. 39, 2240-2252.

Hazen E.L., Horne J.K., 2003, A method for evaluating the effects of biological factors on fish target strength. ICES J. Mar. Sci. 60, $555-562$.

Hazen E.L., Horne J.K., 2004, Comparing the modelled and measured target-strength variability of walleye pollock, Theragra chalcogramma. ICES J. Mar. Sci. 61, 363-377.

Henderson M.J., Horne J.K., 2007, Comparison of in situ, ex situ, and backscatter model estimates of Pacific hake (Merluccius productus) target strength. Can. J. Fish. Aqua. Sci. 64, 1781-1794.

Horne J.K., Walline P.D., Jech J.M., 2000, Comparing acoustic model predictions to in situ backscatter measurements of fish with dualchambered swimbladders. J. Fish Biol. 57, 1105-1121.

ICES, 2007, Collection of acoustic data from fishing vessels. ICES CRReport No. 287.83 pp.

Kloser R.J., Horne J.K., 2003, Characterizing uncertainty in targetstrength measurements of a deepwater fish: orange roughy (Hoplostethus atlanticus). ICES J. Mar. Sci. 60, 516-523.

Korneliussen R.J., Diner N., Ona E., Berger L., Fernandes P.G., 2008, Proposals for the collection of multifrequency acoustic data. ICES J. Mar. Sci. 65, 982-994.

Love R.H., 1977, Target strength of an individual fish at any aspect. J. Acoust. Soc. Am. 62, 1397-1403.

Macaulay G.J., 2002, Anatomically detailed acoustic scattering models of fish. Bioacoustics 12, 275-277.

Macaulay G.J., Peña H., Fässler S.M.M., Pedersen G., Ona E., 2013, Accuracy of the Kirchhoff-approximation and Kirchhoff-RayMode fish swimbladder acoustic scattering models. PLoS ONE 8, e64055.

MacLennan D.N., 1990, Acoustical measurement of fish abundance. J. Acoust. Soc. Am. 87, 1-15.

MacLennan D.N., Menz A., 1996, Interpretation of in situ targetstrength data. ICES J. Mar. Sci. 53, 233-236.

McAllister M.K., Kirkwood G.P., 1998, Bayesian stock assessment: a review and example application using the logistic model. ICES J. Mar. Sci. 55, 1031-1060.

McCartney B.S., Stubbs A.R., 1971, Measurements of the acoustic target strengths of fish in dorsal aspect, including swimbladder resonance. J. Sound Vib. 15, 397-420.

McClatchie S., Alsop J., Coombs R.F., 1996, A re-evaluation of relationships between fish size, acoustic frequency, and target strength. ICES J. Mar. Sci. 53, 780-791.

Metropolis N., Rosenbluth A.W., Rosenbluth M.N., Teller A.H., Teller E., 1953, Equation of state calculations by fast computing machines. J. Chem. Phys. 21, 1087.

Nakken O., Olsen K., 1977, Target strength measurements of fish.

Newman S.J., Dunk I.J., 2002, Growth, age validation, mortality, and other population characteristics of the red emperor snapper, Lutjanus sebae (Cuvier, 1828), off the Kimberley Coast of NorthWestern Australia. Estuar. Coast. Shelf Sci. 55, 67-80. 
Newman S.J., Wakefield C., Skepper C., Boddington D., Blay N., Jones R., Wallis D. 2014, North coast demersal fisheries status report. In: Status Reports of the Fisheries and Aquatic Resources of Western Australia 2013/14: The State of the Fisheries; Eds.: W.J. Fletcher and K. Santoro, (Department of Fisheries, Western Australia).

Ona E., 1990, Physiological factors causing natural variations in acoustic target strength of fish. J. Mar. Biol. Assoc. U. K. 70, $107-127$.

Ona E., 2001, Herring tilt angles, measured through target tracking. In Herring: Expectations for a New Millennium. Ed. by F. Funk, J. Blackburn, D. Hay, A. J. Paul, R. Stephenson, R. Toresen, and D. Witherell. University of Alaska, Sea Grant, AK-SG-01-04. Fairbanks. 800 p.

Ona E., 2003, An expanded target-strength relationship for herring. ICES J. Mar. Sci. 60, 493-499.

Peña H., 2008, In situ target-strength measurements of Chilean jack mackerel (Trachurus symmetricus murphyi) collected with a scientific echosounder installed on a fishing vessel. ICES J. Mar. Sci. 65, 594-604.

Peña H., Foote K.G., 2008, Modelling the target strength of Trachurus symmetricus murphyi based on high-resolution swimbladder morphometry using an MRI scanner. ICES J. Mar. Sci. 65, 17511761.
R Core Team, 2016, R: A language and environment for statistical computing. R Foundation for Statistical Computing, Vienna, Austria. https://www.R-project.org/.

Reeder D.B., Jech J.M., Stanton T.K., 2004, Broadband acoustic backscatter and high-resolution morphology of fish: Measurement and modeling. J. Acoust. Soc. Am. 116, 747-761.

Ryan T.E., Kloser R.J., 2004, Improving the precision of ES60 and EK60 echosounder applications. Rep. Work. Group Fish. Acoust. Sci. Technol. WGFAST 20-23.

Scoulding B., Chu D., Ona E., Fernandes P.G., 2015, Target strengths of two abundant mesopelagic fish species. J. Acoust. Soc. Am. 137, 989-1000.

Simmonds J., MacLennan D., 2005, Fisheries acoustics: theory and practice. Blackwell Publishing, Oxford. $437 \mathrm{p}$.

Soule M., Barange M., Hampton J., 1995, Evidence of bias in estimates of target strength obtained with a split-beam echo-sounder. ICES J. Mar. Sci. 52, 139-144.

Soule M., Barange M., Solli H., Hampton I., 1997, Performance of a new phase algorithm for discriminating between single and overlapping echoes in a split-beam echosounder. ICES J. Mar. Sci. 54, 934-938.

Ye Z., 1997, Low-frequency acoustic scattering by gas-filled prolate spheroids in liquids. J. Acoust. Soc. Am. 101, 1945-1952. 